\title{
A MUTAÇÃO CONSTITUCIONAL COMO MECANISMO DE ADAPTAÇÃO DA CONSTITUIÇÃO BRASILEIRA À REALIDADE POLÍ́TICA E SOCIAL
}

\author{
THE CONSTITUTIONAL MUTATION AS A MECHANISM OF ADAPTATION OF \\ BRAZILIAN CONSTITUTION TO THE POLITICAL AND SOCIAL REALITY
}

\author{
Karen Karolyna Silva Rocha ${ }^{1}$ \\ Manuel Fondevila Marón²
}

\begin{abstract}
Resumo
Analisa-se a mutação constitucional como mecanismo alternativo de adaptação da Constituição brasileira às transformações políticas e sociais, considerando que o seu conteúdo normativo não se realiza por si próprio e há contínua tensão entre estabilidade e dinamicidade do ordenamento jurídico. Apresenta-se o intenso processo de reforma da Constituição de 1988 por meio das emendas e se propõe uma reflexão sobre a mutação constitucional enquanto mecanismo alternativo de modificação constitucional, observada a supremacia da Constituição e o controle a ser exercido pela Corte Constitucional. A abordagem da pesquisa é qualitativa e os procedimentos metodológicos são pesquisa bibliográfica e documental.
\end{abstract}

Palavras-chave: Constituição; Mutação constitucional; Reforma Constitucional; Emenda; Corte Constitucional.

\begin{abstract}
Analyzes the constitutional mutation as an alternative mechanism to adapt the Brazilian Constitution to the political and social transformations, considering that normative content is not done by itself and there is continuous tension between stability and dynamics of the legal system. It shows the intense process of reform of the Constitution of 1988 through amendments and proposes a reflection about the constitutional mutation as an alternative mechanism for constitutional change, observed the supremacy of the Constitution and the control to be exercised by the Constitutional Court. The research approach is qualitative and methodological procedures are bibliographical and documentary research.
\end{abstract}

Keywords: Constitution; Constitutional change; Constitutional reform; Amendment; Constitutional Court;

\footnotetext{
${ }^{1}$ Mestranda do Programa de Pós-Graduação em Direito e Instituições do Sistema de Justiça da Universidade Federal do Maranhão, UFMA - MA, (Brasil). E-mail: karenksrocha@yahoo.com.br

${ }^{2}$ Possui Doutorado pela Universidade de Coruna (Espanha). Professor Visitante da Universidade Federal do Maranhão, UFMA - MA, (Brasil). E-mail: m.fondevila.m@gmail.com
} 


\section{INTRODUÇÃO}

O presente artigo tem por objeto de investigação as mutações constitucionais. Partese do pressuposto de que o caráter dinâmico das relações políticas e sociais propicia o redimensionamento da realidade normativa-constitucional por meio da reforma e também por mudanças informais da Constituição, estas últimas denominadas de mutações constitucionais.

Assim, busca-se responder à seguinte problematização: as mutações constitucionais podem ser um mecanismo alternativo à reforma da Constituição Federal brasileira para adequá-la às constantes transformações políticas e sociais?

O objetivo principal da pesquisa é analisar em que medida a mutação constitucional pode ser uma alternativa à reforma da Constituição brasileira de 1988, a fim de adequá-la à realidade política e social em constante transformação, e tendo em vista o uso desenfreado das emendas constitucionais pelo poder constituinte derivado reformador, ainda que a princípio os seus limites formais e materiais estabelecidos no art. 60 da Constituição Federal sejam respeitados.

Reflete-se, inicialmente, a relação entre Constituição e sociedade, ressaltando a importância da supremacia constitucional e o necessário equilíbrio entre o princípio da segurança jurídica e o acompanhamento pelo direito do dinamismo político-social.

Visa-se, ainda, compreender a mutação constitucional, a partir da compreensão de sua definição, características e tipos, bem como a problemática dos costumes e convenções constitucionais como mecanismos informais de modificação da Constituição.

Objetiva-se, por fim, demonstrar que as mutações encontram limitações na supremacia da Constituição e no conjunto de direitos garantidos aos cidadãos, bem como que cabe ao Supremo Tribunal Federal, enquanto defensor da Constituição, fazer o controle da aplicação das mutações constitucionais no ordenamento brasileiro.

A constante reforma da Constituição de 1988, que em pouco mais de vinte e sete anos de vigência já foi emendada noventa e duas vezes, assim como a sua pouca efetividade, despertam questionamentos sobre a possibilidade de utilização de mecanismos alternativos de modificação das Constituições, como as mutações constitucionais. É nesse contexto que se 
justifica a necessidade de aprofundar os estudos sobre o tema no âmbito da teoria constitucional, como se pretende no presente artigo, mesmo que de forma inicial.

Quanto à metodologia - a partir de uma perspectiva do antiformalismo democrático frente ao formalismo indiferente - a abordagem será qualitativa, pela riqueza de significados que o tema das mutações constitucionais oferece e que não poderiam ser apreendidos pela simples análise de indicadores quantitativos. Para Minayo (2013), a pesquisa qualitativa nas Ciências Sociais se ocupa com um nível de realidade que não pode ou não deveria ser quantificado, uma vez que trabalha com o universo dos significados, dos motivos, das aspirações, das crenças, dos valores e das atitudes. Finalmente, como procedimentos metodológicos, a pesquisa é bibliográfica - utilizando-se livros e artigos de autores clássicos e atuais - e documental, a partir da análise da Constituição Federal e suas emendas.

\section{CONSTITUIÇÃO E SOCIEDADE}

Considerações sobre a supremacia constitucional, a segurança jurídica e a evolução política e social

O direito não deve ser criado em um recipiente hermeticamente fechado e apartado do corpo social. Ao contrário, o ordenamento jurídico retira o seu fundamento de validade da multiplicidade dos relacionamentos sociais, principalmente a Constituição, razão pela qual se torna indispensável a existência de mecanismos que possibilitem a adequação do conteúdo das normas constitucionais aos contornos da sociedade que constitui, sem necessariamente haver a mudança do texto.

Como cediço, a Constituição é a norma fundamental e suprema do Estado, que rege a organização e o funcionamento deste. Para Canotilho (2003), os vários movimentos constitucionais (cujos principais são o inglês, o americano e o francês) convergiram no sentido da existência de um governo limitado com fins garantísticos, e legitimaram o aparecimento da chamada constituição moderna.

Para o constitucionalista português, "por constituição moderna entende-se a ordenação sistemática e racional da comunidade política através de um documento escrito no qual se declaram as liberdades e os direitos e se fixam os limites do poder político". (CANOTILHO, 2003, p. 52)

Várias são as concepções de Constituição, dentre as quais cabe destacar a clássica concepção sociológica de Lassalle, segundo a qual Constituição real de um Estado não passa 
da soma dos fatores reais de poder que imperam na respectiva sociedade. Para o autor, os fatores reais de poder, categoria que estruturou toda a sua teoria, é o conjunto das forças vivas que atuam politicamente na sociedade, ou seja, com base na lei, e eram representadas pela monarquia, a aristocracia, a burguesia e os banqueiros, considerando a Alemanha do século XIX. (LASSALLE, 1988)

Para Ramos (2012), Lassalle trabalha o conceito de Constituição no sentido material, real, isto é, aquele que resulta do pacto realizado pelos fatores reais de poder que atuam em uma dada sociedade.

É importante ainda que se diga que o sentido material dado por Ferdinand Lassalle à Constituição é diferente do sentido moderno de Constituição material. Constituição material, no sentido moderno, é aquela que faz alusão à garantia efetiva dos direitos individuais e à limitação real do poder absoluto. Já o sentido material dado por Ferdinand Lassalle à Constituição é mais abrangente, ou seja, diz respeito à verdade da organização de uma dada sociedade, aquela que reflete o impulso da articulação dos fatores reais efetivos de poder. (RAMOS, 2012, p. 40)

Outra concepção significativa é a de Kelsen (concepção jurídica), para quem a Constituição é uma norma jurídica que possui eficácia por si mesma e não retira dos valores que imperam na sociedade o seu fundamento de validade, mas sim da chamada norma fundamental hipotética.

De acordo com Miranda (2011), Kelsen concebe o Direito como ordem normativa, cuja unidade tem de se assentar numa norma fundamental e hierarquicamente superior, qual seja, a Constituição, compreendida em sentido jurídico-positivo e em sentido lógico-jurídico. No primeiro sentido, a Constituição representa o escalão de direito positivo mais elevado que regula a produção das normas jurídicas gerais (legislação). No segundo sentido, a Constituição consiste na norma fundamental hipotética, e por ser a mais elevada é pressuposta e não posta por uma autoridade.

E por fim, importante mencionar a concepção política de Schmitt, segundo a qual a Constituição é uma decisão política fundamental, explicitada pelo poder constituinte e com o objetivo de estruturar e formalizar os elementos fundamentais do Estado. Para o jurista alemão:

La Constitución en sentido positivo surge mediante un acto del poder constituyente. El acto constituyente no contiene como tal unas normaciones cualesquiera, sino, y precisamente por un único momento de decisión, la totalidad de la unidad política considerada en su particular forma de existencia. Este acto constituye la forma y modo de la unidad política, cuya existencia es anterior. No es, pues, que la unidad política surja porque se haya dado una Constitución. La Constitución en sentido positivo contiene sólo la determinación consciente de la unidad política. Esta forma se puede cambiar. Se pueden introducir fundamentalmente nuevas formas sin que el 
Estado, es decir, la unidad política del pueblo, cese. Pero siempre hay en el acto constituyente un sujeto capaz de obrar, que lo realiza con la voluntad de dar una Constitución. Tal Constitución es una decisión consciente que la unidad política, a través del titular del poder constituyente, adopta por sí misma e se da a sí misma. ${ }^{3}$ (SCHMITT, 2011, p. 58)

A despeito da concepção que seja adotada, o importante é a compreensão da Constituição como norma fundamental suprema, ocupando uma posição hierárquica superior relativamente às outras normas do ordenamento jurídico.

Além disso, a Constituição não é uma simples carta de direcionamento político ou uma declaração valorativa de intenções. Ela é uma lei vinculativa dotada de efetividade e aplicabilidade, ou seja, possui força normativa, ainda que suas normas possuam graus diferentes de eficácia e aplicabilidade. ${ }^{4}$

Para Canotilho (2003), a superioridade hierárquico-normativa da Constituição apresenta três expressões: $1^{\text {a }}$ ) a autoprimazia normativa, que significa que as normas constitucionais não derivam sua validade de outras normas, mas de si própria; $2^{\text {a }}$ ) as normas constitucionais são normas de normas, ou seja, fonte primária da produção jurídica, de modo que os demais atos legislativos encontram o seu fundamento de validade na Constituição que está no topo da pirâmide jurídica; $3^{\mathrm{a}}$ ) a superioridade normativa das normas constitucionais implica o princípio da conformidade de todos os atos dos poderes públicos com a Constituição, seja como determinantes negativas, limitando as normas inferiores, seja como determinantes positivas, ao regular o próprio conteúdo das normas inferiores.

A supremacia da Constituição também está intimamente ligada à sua estabilidade. Contudo, já restou ultrapassada a ideia de uma Constituição imutável sob o fundamento de

\footnotetext{
3 “A Constituição em sentido positivo surge por ato do poder constituinte. O ato constituinte não contém quaisquer normas, mas, e precisamente por um único momento de decisão, a totalidade da unidade política considerada em sua forma particular de existência. Este ato constitui a forma e o modo da unidade política, cuja existência é anterior. Não é, pois, que a unidade política surge porque haja uma dada Constituição. A Constituição em sentido positivo contém apenas a determinação consciente da unidade política. Esta forma pode ser alterada. Podem-se introduzir novas formas sem que o Estado, ou seja, a unidade política do povo, acabe. Mas há sempre no ato constituinte um sujeito capaz de agir, que o faz com a vontade de dar uma Constituição. Tal Constituição é uma decisão política consciente que a unidade política, através do titular do poder constituinte, adota para si mesma e dá a si mesma." (tradução nossa)

${ }^{4}$ A doutrina constitucional costuma classificar as normas constitucionais quanto ao grau de eficácia e aplicabilidade. A classificação mais conhecida na doutrina brasileira é a de José Afonso da Silva, que estabelece três grupos distintos: $1^{\circ}$ ) normas de eficácia plena - aquelas que estão aptas a produzir os seus efeitos integrais desde a entrada em vigor da Constituição, independentemente de regulação por lei; $2^{\circ}$ ) normas de eficácia contida ou restringível - aquelas que também estão aptas a produzir efeitos, direta e imediatamente, com a simples entrada em vigor da Constituição, mas que podem ser restringidas posteriormente por lei, por outras normas constitucionais ou por conceitos éticos-jurídicos; e $3^{\circ}$ ) normas de eficácia limitada - aquelas que só produzem seus plenos efeitos depois da regulamentação exigida pela Constituição. (SILVA, 2007).
} 
que por ser a lei suprema, por regular as atribuições e competências do Estado, assim como por garantir os direitos fundamentais dos cidadãos, deve ela ser perpétua.

As constituições, assim como todo o ordenamento jurídico, devem acompanhar as contínuas transformações políticas e sociais, o que não implica necessariamente que tudo deva ser expressamente regulado por lei, muito menos na Constituição, nos mínimos detalhes, pela própria impossibilidade de prever todas as situações e relações humanas.

Além disso, mudanças constantes na Constituição enfraquecem sua autoridade normativa, especialmente ao torná-las mais analíticas e sobrecarregadas com normas apenas formalmente constitucionais. Ou ainda, quando são desconsiderados os limites à reforma constitucional. A fraca estabilidade constitucional se traduz em insegurança jurídica.

Hesse (1991, p. 22) já havia alertado para o fato de que "a frequência das reformas constitucionais abala a confiança na sua inquebrantalidade, debilitando a sua força normativa. A estabilidade constitui condição fundamental da eficácia da Constituição”.

A segurança jurídica é um direito fundamental e princípio constitucional. Para Clève e Lorenzetto:

\begin{abstract}
A segurança jurídica exige um conjunto normativo apto a solucionar controvérsias judiciais e, mais do que isso, uma arquitetura institucional dotada de capacidade para a produção de decisões justas, nesse contexto, o reconhecimento de uma dimensão material ou valorativa é inafastável, qualificando-a como um instrumento a serviço dos cidadãos para o controle da atuação do Poder Público. (2016, p. 184)
\end{abstract}

Em sua dimensão objetiva, a segurança jurídica implica observar a certeza e a previsibilidade. Significa dizer que em face da tipicidade da norma, não há espaço para a discricionariedade, e cabe ao legislador (bem como aos juízes) ser claro e racional, especialmente ao tratar de proibições às liberdades dos indivíduos. Sob um viés subjetivo, por sua vez, a segurança jurídica refere-se à confiança dos cidadãos na continuidade do ordenamento jurídico, das instituições e também do pensamento jurisprudencial, para assim poderem agir em conformidade com eles. (CLÈVE e LORENZETTO, 2016)

Portanto, as modificações constitucionais devem levar em conta também a tensão existente entre a segurança jurídica e a necessária atualização normativa para atender à dinamicidade da realidade política e social. 
A maioria das constituições modernas é considerada rígida, como é o caso da Constituição brasileira de $1988^{5}$. Significa dizer que elas admitem alterações em seu texto, mas exigem um processo legislativo especial, solene, mais complexo do que aquele de elaboração das demais normas no ordenamento jurídico. ${ }^{6}$

Assim, as alterações formais da Constituição são feitas pelo processo de reforma constitucional. Todavia, seria a reforma constitucional o mecanismo mais adequado e producente de adaptação da Constituição às transformações políticas e sociais, principalmente em sociedades pluralistas e dinâmicas como a sociedade brasileira? A mutação constitucional seria uma opção mais proveitosa de adequação entre a realidade jurídica e a realidade política? Quais os seus limites e por quem ela deve ser realizada?

$\mathrm{Na}$ seção seguinte analisa-se a mutação constitucional e propõem-se algumas reflexões a respeito da sua aplicabilidade no contexto brasileiro, no qual se questiona a própria efetividade da Constituição de 1988.

\section{A MUTAÇÃo CONSTITUCIONAL COMO ALTERNATIVA À REFORMA DA CONSTITUIÇÃO BRASILEIRA}

Como sabido, as mudanças formais ao texto da Constituição são feitas pela via prevista na própria Lei superior, denominada reforma constitucional e realizada por mecanismos como a emenda. Todavia, a Constituição também sofre alterações que estão à margem dos procedimentos formais previstos para tal efeito.

Essas alterações, sejam elas formais ou informais, são imprescindíveis para a própria manutenção do ordenamento constitucional, sob pena de se estar diante do que Loewenstein (1979) chamou de Constituição nominativa, ou seja, aquela que embora elaborada com o intuito de regular a vida política do Estado, não consegue efetivamente cumprir o seu papel, pois está em descompasso com a realidade do Estado e não acompanha a dinâmica política e social.

\footnotetext{
${ }^{5}$ À exceção da Constituição Imperial de 1824, que foi do tipo semirrígida (isto é, parte do seu texto era rígido e requeria um processo legislativo especial para alteração, e a outra parte era flexível, podendo ser modificada por um processo legislativo simples), todas as demais Constituições brasileiras foram do tipo rígida.

${ }^{6}$ Interessante destacar a reflexão feita por De Vega (2007) quanto à supremacia e rigidez constitucionais na atualidade. Para o autor, não obstante a Constituição inglesa, que não é escrita, seja definida como flexível, em realidade ela representa um dos poucos exemplos dignos de menção como exceção à regra da rigidez. Na GrãBretanha o Parlamento não prescinde da opinião pública, de modo que lá as reformas constitucionais são muito mais difíceis que em Estados que possuem constituições escritas e rígidas, a exemplo da Espanha.
} 
As mutações constitucionais, que em termos gerais são compreendidas como modificações não formais ao ordenamento constitucional e que definem um novo campo semântico sem a alteração do texto, por meio da interpretação constitucional ${ }^{7}$, ainda são um tema controverso na doutrina, a iniciar pela própria denominação.

Os autores utilizam terminologias distintas para tratar das mudanças não formais na Constituição. Para citar alguns: Jorge Miranda prefere o termo vicissitude constitucional tácita, compreendendo as modificações trazidas pelo costume praeter e contra legem, assim como as que resultam da interpretação evolutiva da Constituição; Gomes Canotinho emprega a expressão transições constitucionais, para referir-se às revisões informais que mudam o sentido, mas não o texto da Constituição; Pietro Merola Chierchia utiliza a terminologia processos de fato; Luís Pinto Ferreira adere à expressão mudança material; e Anna Cândida da Cunha Ferraz se utiliza das expressões processos indiretos, processos não formais ou informais. (BULOS, 1996)

O certo é que independentemente da nomenclatura adotada, as concepções convergem para a mesma ideia da existência de alterações da Constituição sem mudar o texto e que geralmente só são percebidas pela comparação dos entendimentos declarados pelos aplicadores e intérpretes da Constituição ao longo do tempo.

Neste artigo, será empregado o termo mutação constitucional amplamente aceito pela doutrina constitucionalista estrangeira e nacional.

\subsection{Delineamentos das Mutações Constitucionais}

Jellinek foi um dos doutrinadores que traçou os primeiros contornos do conceito de mutação constitucional (Verfassungswandlung) na Alemanha, no início do século XX, distinguindo-a da reforma constitucional (Verfassungsänderung).

Para Jellinek (1991), a reforma constitucional é a modificação dos textos constitucionais produzida por ações voluntárias e intencionadas, enquanto a mutação constitucional é a modificação que não altera formalmente o texto da Constituição e se produz por fatos que não necessitam estar acompanhados da intenção ou consciência de tal mutação.

\footnotetext{
${ }^{7}$ Para García Belaunde podem ser incluídos como critérios orientadores da interpretação constitucional: primar a presunção de constitucionalidade; buscar a concordância da Constituição consigo mesma; prevalência da razoabilidade, que difere do racional; previsão de consequências; preferência pelos direitos humanos; fórmula política. Häberle, por sua vez, apresenta os seguintes princípios para a interpretação constitucional: unidade da Constituição; unidade prática (ou de equilíbrio); interpretação conforme o texto constitucional; interpretação favorável ao Direito Internacional; e conforme ao Direito Comparado. (PEGORARO, em fase de elaboração)
} 
Bulos também destaca a contribuição da doutrina alemã para a compreensão do fenômeno da mutação constitucional:

\begin{abstract}
Parece ter sido a doutrina alemã que primeiro detectou o problema, ao notar que a Constituição de 1871 sofria, frequentemente, mudanças quanto ao funcionamento das instituições do Reich - mudanças estas que ocorriam sem reformas constitucionais. Foi aí que Laband, examinando o aludido texto constitucional alemão de 1871, notou importantes modificações neste Diploma Maior, para acompanhar a situação constitucional do Império (verfassunszustand), distinguindo a verfassungänderung (reforma constitucional) da verfassungswandel (mutação constitucional). (1996, p. 26)
\end{abstract}

Para Lucas Verdú (1984, p.193), "las mutaciones constitucionales, en la medida en que arrancan y se apoyan en la realidad constitucional, introducen en el texto fundamental rígido dosis de flexibilidad de suerte que cooperan a su elasticidad". 8

As circunstâncias que explicam a existência das mutações constitucionais são a necessária dinamicidade imposta ao ordenamento constitucional pela realidade política e social, assim como a indispensável complementariedade entre a reforma e a mutação, como mecanismos não excludentes de adaptação da Constituição. Ressalta-se, ainda, o fato de que a reforma deverá ser utilizada apenas em circunstâncias extremas, ou seja, bem menos que as mutações constitucionais. (DE VEGA, 2007)

Quanto aos tipos de mutações constitucionais, a classificação mais completa é a de Hsü Dau-Lin (1998), que distingue quatro espécies: $1^{\text {a }}$ ) aquelas devidas a práticas políticas que não se opõem formalmente à Constituição escrita, e para cuja regulação não exista nenhuma norma constitucional; $2^{\mathrm{a}}$ ) aquelas devidas a práticas políticas em oposição aberta a preceitos da Constituição, e os fatos se sobrepõem às normas; $3^{\text {a }}$ ) aquelas produzidas pela impossibilidade do exercício, ou pelo desuso, das competências e atribuições estabelecidas na Constituição; $4^{\mathrm{a}}$ ) aquelas produzidas através da interpretação do texto constitucional, de modo que os preceitos adquirem um conteúdo distinto daquele que inicialmente foi pensado.

Considerando a classificação de Hsü Dau-Lin, De Vega (2007), afirma que as mutações procedem de fontes diversas, como os órgãos estatais, adquirindo caráter de atos jurídicos de natureza normativa (leis, regulamentos) ou de natureza jurisdicional (sentenças dos Tribunais Constitucionais). Mas também podem proceder de simples práticas políticas,

\footnotetext{
8 "as mutações constitucionais, na medida em que emergem e se apoiam na realidade constitucional introduzem no texto fundamental rígido doses de flexibilidade, de sorte que cooperam para a sua elasticidade." (tradução nossa)
} 
que podem se converter em normas de natureza político-social (convenções), ou se convertem em fatos jurídicos (costumes).

Aduz Pegoraro (em fase de elaboração), que aos processos expressamente previstos para reformar os textos constitucionais, operam outros procedimentos de reforma, como as convenções constitucionais ou os costumes, assim como os que decorrem da legislação que desenvolve os preceitos constitucionais. Além disso, as revisões informais também podem ser feitas pelas Cortes Constitucionais, seja pela atividade interpretativa ou pela participação no procedimento de reforma.

\begin{abstract}
Entre os modos implícitos de modificação das Constituiç̃̃es o primeiro que deve ser considerado é aquele que se realiza mediante as convenções e os costumes constitucionais. Em âmbito constitucional, nem sempre é possível distinguir as convenções dos costumes. Substancialmente, as primeiras são regras autônomas, que vinculam, sempre que as relações não mudem, aos sujeitos institucionais que as estipularam. A violação das convenções, segundo a muito conhecida formulação de A.V. Dicey, não pode, entretanto, ser sancionada por parte dos juízes (mas, pode ser reconhecida por estes, como acontece na jurisprudência canadense e a israelita). As segundas são regras heterônomas, que se impõe a todos, e que tem a hierarquia própria das fontes às quais se referem e, como tal, manifestam a sua eficácia, inclusive - embora na atualidade muito raramente - com efeitos ab-rogativos. (PEGORARO, p. 5-6, em fase de elaboração)
\end{abstract}

Os costumes e as convenções são considerados por alguns doutrinadores ${ }^{9}$ como modos implícitos de modificação das Constituições, especialmente das consideradas flexíveis ou em ordenamentos que não possuem Constituições formais (escritas), como o Reino Unido. Mas as alterações constitucionais através dos costumes e convenções também estão presentes em ordenamentos de constituições rígidas, sendo utilizados quando determinada norma é imprecisa ou vaga.

Os costumes caracterizam-se pela reiteração de comportamentos que possuem força jurídica vinculante. Ademais, não admitem graus, ou seja, não é possível fazer a distinção entre os costumes constitucionais e os demais costumes, como se faz a distinção entre a Constituição e as leis infraconstitucionais. Os costumes constitucionais somente existem se derivados de usos e comportamentos de natureza constitucional, e são protagonizados pelos titulares dos órgãos e poderes do Estado.

De Vega (2007) detém posição distinta, considerando que as mutações constitucionais não podem ser conduzidas por normas consuetudinárias, posto que essas

\footnotetext{
${ }^{9} \mathrm{Um}$ dos autores que consideram os costumes e as convenções constitucionais como mecanismos de mutação constitucional é Pegoraro (em fase de elaboração).
} 
normas carecem no direito constitucional do significado e alcance que adquirem em outros ramos do direito.

Quanto aos atos normativos (leis complementares, leis ordinárias, leis orgânicas, regimentos, regulamentações etc.), contribuem os mesmos para a mutação constitucional ao definirem o significado de termos constitucionais, reduzindo ou ampliando o seu significado original.

Uma Constituição (flexível ou rígida) pode ser desenvolvida, integrada e, até certo ponto, modificada, através de legislação de desenvolvimento nominal, isto é, por leis que estão explicitamente previstas na Constituição, ou pela legislação "livre" (discricionária). Ela pode ser reformada, além disso, por fontes diferentes da lei, e outras vezes, inclusive, pela ausência de atuação das instituições nela previstas. (PEGORARO, p. 7, em fase de elaboração)

Conforme afirma De Vega (2007), não causam estranheza as mutações constitucionais derivadas de atos legislativos. Em primeiro lugar, em virtude da própria natureza vaga e principiológica de muitas normas constitucionais que exigem para sua aplicação um desenvolvimento legislativo posterior; em segundo lugar, porque as constituições modernas são produto do consenso de distintas forças políticas, cujo resultado são disposições ambíguas ou mesmo contraditórias entre si; e em terceiro lugar, porque em muitas ocasiões são as próprias constituições que reenviam ao legislador a tarefa de desenvolver seus preceitos. Ressalta o autor, contudo, que não se pode admitir a modificação legal da Constituição, sem recorrer ao procedimento da reforma.

Quanto às mutações decorrentes da atuação das Cortes Constitucionais, elas advêm da própria função jurisdicional, da atividade interpretativa, e serão mais frequentes quanto mais genéricas e indeterminadas forem as normas da Constituição. ${ }^{10}$

O que deve estar claro para os juízes que atuam nas Cortes Constitucionais é que eles não podem atribuir significado às normas constitucionais que ofendam o seu núcleo duro e a sua supremacia. Devem atuar nos limites da ordem constitucional e buscando acoplar realidade e facticidade.

\footnotetext{
${ }^{10}$ Pegoraro (em fase de elaboração) reflete sobre os "estilos" de Constituição e a relação com a revisão constitucional. Destaca o exemplo da Constituição americana que aspirou durar por séculos, razão pela qual suas normas são mais vagas, genéricas e indeterminadas. Já em posição oposta, cita o autor o exemplo das Constituições sul-africanas de 1983, de 1993 e de 1996-97, cujas redações minuciosas não deixavam espaço para a causalidade. Para o autor, as Constituições que seguem o "estilo" indeterminado da americana, deixam aos intérpretes (legislador, administração, juízes, e sobretudo à Corte Constitucional) decidir em conformidade com a evolução social.
} 
3.2 Emenda Constitucional vs. Mutação Constitucional: uma análise da realidade brasileira pós-1988

A Constituição da República Federativa do Brasil atualmente vigente foi promulgada em 05 de outubro de 1988 por uma Assembleia Nacional Constituinte, com 250 artigos, além das disposições constitucionais transitórias ${ }^{11}$.

O poder constituinte originário também estabeleceu a possibilidade de mudança da Constituição por meio de dois processos distintos: a revisão constitucional (poder constituinte derivado revisor) e a emenda à Constituição (poder constituinte derivado reformador).

Quanto à primeira, estabelece o art. $3^{\circ}$ do Ato das Disposições Constitucionais Transitórias - ADCT que “a revisão constitucional será realizada após cinco anos, contados da promulgação da Constituição, pelo voto da maioria absoluta dos membros do Congresso Nacional, em sessão unicameral".

No prazo estabelecido o Congresso Nacional instalou a Assembleia Revisional que instituiu seis emendas constitucionais revisionais: a ECR $\mathrm{n}^{\circ}$ 01, de 01/03/1994, que acrescentou os artigos 71, 72 e 73 ao ADCT; a ECR nº 02, de 07/06/1994, que alterou o caput do art. 50 e seu $\S 2^{\circ}$ da CF; a ECR n 03, de 07/06/1994, que alterou a alínea “c”, do inciso I, a alínea "b", do inciso II, o $\S 1^{\circ}$ e o inciso II do $\S 4^{\circ}$ do art. 12 da CF; a ECR $n^{\circ}$ 04, de 07/06/1994, que alterou o $\$ 9^{\circ}$ do art. 14 da CF; a ECR nº 05, de 07/06/1994, que alterou o art. 82 da CF; e a ECR nº 06, de 07/06/1994, que acrescentou o $\$ 4^{\circ}$ ao art. 55 da CF.

A revisão constitucional foi um procedimento simplificado, principalmente tendo em vista que o plebiscito de 1993, previsto no art. $2^{\circ}$ do $\mathrm{ADCT}^{12}$, confirmou a forma de governo republicana e o sistema de governo presidencialista estabelecidos pelo constituinte originário. Portanto, a revisão constitucional acabou por ficar praticamente sem objeto, e foram apenas aprovadas as seis emendas revisionais em um turno de votação e por maioria absoluta, ou

\footnotetext{
${ }^{11}$ O Ato das Disposições Constitucionais Transitórias - ADCT, reúne normas constitucionais de cunho transitório, que podem ser divididas em dois grupos distintos: a) aquelas que estabeleceram regras de transição do regime constitucional pretérito $(\mathrm{CF} / 1969)$ para o regime atual $(\mathrm{CF} / 1988)$; e b) aquelas que têm caráter meramente transitório, com eficácia jurídica limitada no tempo. As normas integrantes do ADCT têm a mesma força normativa e hierarquia das normas constitucionais permanentes e só podem ser alteradas por meio de emenda à Constituição. Além disso, podem ser parâmetro para o controle da constitucionalidade das leis.

${ }^{12}$ Art. $2^{\circ}$ do ADCT: "No dia 7 de setembro de 1993 o eleitorado definirá, através de plebiscito, a forma (república ou monarquia constitucional) e o sistema de governo (parlamentarismo ou presidencialismo) que devem vigorar no País".
} 
seja, procedimento menos rígido do que o previsto no art. 60 para a aprovação das emendas constitucionais. ${ }^{13}$

Foi também um procedimento único, realizado após cinco anos de promulgação da Constituição Federal. Portanto, não é juridicamente possível realizar uma nova revisão constitucional com fundamento no art. $3^{\circ}$ do ADCT, cuja eficácia já se esgotou. Não cabe ao Congresso Nacional aprovar emenda à Constituição criando um novo procedimento simplificado de revisão constitucional, de modo que a atual Constituição só poderá ser modificada formalmente pelo procedimento rígido de emenda.

A possibilidade de emendar a Constituição está prevista no seu artigo 60:

Art. 60. A Constituição poderá ser emendada mediante proposta:

I - de um terço, no mínimo, dos membros da Câmara dos Deputados ou do Senado Federal;

II - do Presidente da República;

III - de mais da metade das Assembleias Legislativas das unidades da Federação, manifestando-se, cada uma delas, pela maioria relativa de seus membros.

$\S 1^{\circ}$ A Constituição não poderá ser emendada na vigência de intervenção federal, de estado de defesa ou de estado de sítio.

$\S 2^{\circ}$ A proposta será discutida e votada em cada Casa do Congresso Nacional, em dois turnos, considerando-se aprovada se obtiver, em ambos, três quintos dos votos dos respectivos membros.

$\S 3^{\circ} \mathrm{A}$ emenda à Constituição será promulgada pelas Mesas da Câmara dos Deputados e do Senado Federal, com o respectivo número de ordem.

$\S 4^{\circ}$ Não será objeto de deliberação a proposta de emenda tendente a abolir:

I - a forma federativa de Estado;

II - o voto direto, secreto, universal e periódico;

III - a separação dos Poderes;

IV - os direitos e garantias individuais.

$\S 5^{\circ}$ A matéria constante de proposta de emenda rejeitada ou havida por prejudicada não pode ser objeto de nova proposta na mesma sessão legislativa.

Ao longo dos seus pouco mais de vinte e sete anos de vigência, a Constituição brasileira já foi emendada noventa e duas vezes, sendo a primeira emenda constitucional de 31 de março de $1992^{14}$ e a última de 12 de julho de $2016^{15}$.

\footnotetext{
${ }^{13} \mathrm{Na}$ época em que foi elaborada a Constituição, os constituintes resolveram possibilitar aos brasileiros, após cinco anos de vigência da Lei Maior recém promulgada, decidir sobre a forma e o sistema de governo em plebiscito. Desse modo, em caso de alteração para a monarquia e o parlamentarismo, seria necessária a adaptação do texto constitucional às mudanças, uma vez que ele foi todo elaborado com a adoção da república e do presidencialismo. Para facilitar as adaptações é que foi prevista a revisão constitucional para logo após o plebiscito.
} 
Entre as emendas mais significativas pode-se citar a $\mathrm{EC} \mathrm{n}^{\circ} 19$, de 04/06/1988 que ao modificar o regime e dispor sobre princípios e normas da Administração Pública, servidores e agentes políticos, controle de despesas e finanças públicas e custeio de atividades a cargo do Distrito Federal, estabeleceu a reforma administrativa no Estado brasileiro.

Outra modificação formal importante foi a $E C \mathrm{n}^{\circ} 45$, de 30/12/2014 que realizou a chamada reforma do Judiciário com a ampliação das competências da justiça do trabalho, a consagração do princípio da razoável duração do processo, a instalação do Conselho Nacional de Justiça e a inclusão de regra sobre o status constitucional dos tratados e convenções internacionais sobre direitos humanos ${ }^{16}$.

O procedimento de emenda à Constituição brasileira é bastante rígido, porém, o seu uso se tornou uma constante, colocando em cheque a própria supremacia e efetividade da Constituição Federal, assim como a segurança jurídica do ordenamento pátrio.

Não basta que sejam respeitados os limites processuais como a iniciativa restrita ou o quórum de deliberação, ou ainda, os limites circunstanciais que proíbem a modificação do texto constitucional durante o estado de defesa, o estado de sítio e a intervenção federal.

Também não são suficientes os limites materiais explícitos que constam no parágrafo $4^{\circ}$, do art. 60 da CF (forma federativa, voto direto, secreto, universal e periódico, separação de poderes e direitos e garantias individuais), considerados cláusulas pétreas, bem como limites materiais implícitos, como a impossibilidade de alteração do próprio procedimento de modificação da Constituição Federal.

O que se está a questionar é a utilização exacerbada e periódica do procedimento de reforma que poderá comprometer toda a estrutura normativa e levar à fragmentação da Constituição.

Para Clève e Lorenzetto:

Há um descrédito na força normativa se a Constituição é revisada periodicamente em decorrência de necessidades políticas elementares. Logo, entende-se que deve ser estabelecido um rol robusto e perene de motivações para que um conjunto de

\footnotetext{
${ }^{14}$ Dispõe sobre a remuneração dos Deputados Estaduais e dos Vereadores.

15 Altera os arts. 92 e 111-A da Constituição Federal, para explicitar o Tribunal Superior do Trabalho como órgão do Poder Judiciário, alterar os requisitos para o provimento dos cargos de Ministros daquele Tribunal e modificar-lhe a competência. Até o momento de conclusão da pesquisa (agosto de 2016), a última emenda constitucional foi a de $n^{\circ}$ 92, publicada no DOU em 13/07/2016.

16 Art. $5^{\circ}$, $\$ 3^{\circ}$, da FC/1988: “Os tratados e convenções internacionais sobre direitos humanos que forem aprovados, em cada Casa do Congresso Nacional, em dois turnos, por três quintos dos votos dos respectivos membros, serão equivalentes às emendas constitucionais".
} 
alterações substantivas possa ter lugar na ordem constitucional por meio de uma reforma. (2016, p. 180)

A proposta do presente artigo é que as mutações constitucionais sejam uma alternativa à reforma da Constituição brasileira, já emendada mais de noventa vezes em menos de trinta anos, número este bastante elevado se comparado ao número de emendas à Constituição americana de 1787, que além de estar em vigor por mais de dois séculos e possuir apenas sete artigos, apresenta tão somente vinte e sete emendas.

O Supremo Tribunal Federal seria o órgão de destaque para a efetivação da mutação constitucional, a fim de adequar a normatividade-constitucional às transformações políticas e sociais brasileiras. Utilizando-se de princípios interpretativos ${ }^{17}$, o Supremo já utiliza a mutação constitucional ${ }^{18}$, mas a atuação pró-ativa da Corte Suprema não parece inibir a crescente proposição de emendas constitucionais pelos seus legitimados, colocando em discussão a própria efetividade e supremacia da Constituição Federal de 1988 que parece se descaracterizar a cada nova reforma.

\subsection{Limites à Mutação Constitucional}

No tocante aos limites à mutação constitucional, o problema que se levanta é até que ponto o Estado constitucional pode tolerá-las sem que se destrua a lógica e a racionalidade interna do sistema. A problemática dos limites às mutações, portanto, se situa no conflito entre norma e realidade.

Para evitar o aniquilamento da força normativa da Constituição, imprescindível o reconhecimento de certos limites às mutações, os quais podem ser encontrados nos princípios constitucionais que perfazem o seu núcleo duro, como a segurança jurídica.

\footnotetext{
${ }^{17}$ Os principais princípios de interpretação constitucional utilizados pelo STF são: interpretação conforme a Constituição; princípio da unidade da Constituição; do efeito integrador; da harmonização; da máxima efetividade; e da força normativa da Constituição.

${ }^{18}$ Um exemplo de mutação constitucional realizado pelo STF foi a nova interpretação dada ao art. 52, X, da CF/88 que trata da competência do Senado Federal para suspender a execução, no todo ou em parte, de lei declarada inconstitucional por decisão definitiva do STF. Todavia, há autores que contestam a argumentação do Ministro Gilmar Mendes e consideram que o STF interferiu indevidamente em competência do Senado Federal. (SANTOS, 2014). Importante registrar, também, que em pesquisa realizada por Sacchetto (2015) nos julgados efetuados pelo Supremo Tribunal Federal, nos quais a mutação constitucional foi utilizada de forma literal, o autor verificou que o instituto tem sido empregado pelos Ministros em três sentidos distintos: 1) para demonstrar uma simples mudança interpretativa ocorrida sobre o significado de determinado dispositivo legal; 2) para fazer referência a uma alteração formal da Constituição realizada por meio de emenda constitucional; e 3) para abordar um método hermenêutico de atualização da norma a partir de uma alteração ocorrida na realidade dos fatos. Para o autor, o terceiro sentido é que deve ser considerado como verdadeira mutação constitucional.
} 
Ao contrário dos limites à reforma da Constituição que são mais óbvios e em sua maioria expressos no próprio texto constitucional - a exemplo dos limites explícitos no art. 60 da Constituição brasileira à criação de emendas constitucionais -, os limites às mutações são bem mais sutis, seguindo a singularidade do fenômeno e em decorrência da própria informalidade com que ela modifica a semântica do texto constitucional por meio da interpretação.

No caso brasileiro, contudo, nada obsta inferir que os limites materiais inscritos no art.60, $\S 4^{\circ}$, consistentes na forma federativa de Estado, no voto direto, secreto, universal e periódico, na separação de poderes, e nos direitos e garantias individuais também possam ser estendidos como limitações às mutações constitucionais, uma vez que representam a essência da Constituição Federal.

Tendo em vista que a existência da Constituição depende da manutenção da estrutura de governo, do estabelecimento da separação de poderes e da garantia dos direitos fundamentais, qualquer modificação atentatória contra algum desses pilares deve ser rechaçada de imediato.

De Vega (2007) sustenta que o fato da normativa constitucional ser incapaz de assumir todos os aspectos complexos da vida e do Estado, cuja consequência é a admissão das mutações constitucionais, não impede o reconhecimento de que em nenhuma hipótese a característica de Lex superior da Constituição pode ser colocada em dúvida. ${ }^{19}$ A tensão latente entre realidade jurídica (normatividade) e realidade política (facticidade) não obsta a coexistência das mutações constitucionais com o princípio da supremacia constitucional. $\mathrm{Na}$ verdade, o problema dos limites às mutações inicia quando a tensão entre facticidade e normatividade coloca em perigo a própria noção de supremacia e, neste caso, a alternativa é a conversão da mutação em norma (reforma), ou negar o valor jurídico da mutação para que prevaleça a legalidade.

Dicho en otras palabras, la mutación constitucional existe y se tolera por el sistema en la medida en que el conflicto entre realidad y normatividad es latente. Cuando el

\footnotetext{
${ }^{19}$ Para De Vega (2007), a contraposição entre normatividade e facticidade está na base da problemática das mutações constitucionais e apresenta uma tripla ordem de possibilidades: $1^{\mathrm{a}}$ ) quando há o triunfo do fático sobre o normativo que levado a suas últimas consequências poderia levar à destruição do próprio conceito jurídico de Constituição; $2^{a}$ ) o conflito pode ser resolvido por uma dupla alternativa: a) as mudanças operadas previamente na realidade pelas mutações são convertidas em reforma formal, a exemplo da emenda $\mathrm{n}^{\circ} 22$ da Constituição americana; ou b) que a força das normas se faça valer sobre a força dos fatos, como se deu no direito espanhol a partir das sentenças do Tribunal Constitucional 5/1983 e 10/1983, que delimitaram o alcance do mandato representativo; e a $3^{\text {a }}$ ) o conflito tende à busca por um acoplamento, para que realidade jurídica e realidade política possam coexistir.
} 
conflicto estala, y la contraposición entre lo fáctico y lo normativo exige una decisión inexorable, la lógica del Estado constitucional impone el triunfo de la legalidad $^{20}$ (DE VEGA, 2007, p. 210).

Silva (1999) corrobora o entendimento de De Vega, considerando que o conflito entre fato e norma pode ser resolvido por emenda constitucional ou pela prevalência da norma sobre o fato por decisão judicial firme.

É necessário o acoplamento entre o discurso fático e o discurso normativo para que seja aceita a configuração de uma mutação constitucional, seja ela empreendida pelos Tribunais, pelo Executivo ou pelo Legislativo, a fim de evitar que a emergência de realidades políticas contingentes dilapidem os processos democráticos e os direitos fundamentais. (CLÈVE e LORENZETTO, 2016)

\begin{abstract}
A hierarquia normativa, a rigidez constitucional e guardiões da Constituição assentados em uma Corte Suprema, não são dispositivos que buscam uma simples estabilização e imobilização social, ao contrário, são institutos jurídicos orientados para a preservação de valores estimados como fundamentais para a comunidade política e que, por isso, adquirem status jurídico privilegiado no ordenamento normativo. A Constituição e suas cláusulas pétreas podem ser vistos, assim, como limites à mutação constitucional, em especial, em sua modalidade silenciosa. (CLÈVE e LORENZETTO, 2016, p. 83)
\end{abstract}

A explicação da estrutura das normas constitucionais de Müller também é relevante para o estabelecimento de limites às mutações constitucionais. Segundo o autor, a estrutura da norma constitucional é determinada por um programa normativo que constitui a parte integrante da norma em si, e por um âmbito normativo que expressa a realidade ordenada e regulada por ela. Nesse sentido, da mesma forma que não haveria sentido falar de âmbito normativo sem a existência prévia de um programa normativo, também não seria possível um programa normativo que não atenta para a realidade histórica. Portanto, se o programa normativo conforma a realidade, o âmbito normativo não pode deixar de conformar o programa normativo (DE VEGA, 2007).

O reconhecimento da complexidade da realidade constitucional e da importância das mudanças ocorridas no mundo da vida e seus reflexos no âmbito jurídico, formuladas pelo programa da norma supõem a assimilação e a justificação das mutações constitucionais. Os limites, como já ressaltado, dizem respeito à defesa da supremacia da Constituição que não

\footnotetext{
20 "Em outras palavras, a mutação constitucional existe e é tolerada pelo sistema, na medida em que o conflito entre realidade e normatividade é latente. Quando o conflito estala, e a contraposição entre o fático e o normativo exige uma decisão inexorável, a lógica do Estado constitucional impõe o triunfo da legalidade." (tradução nossa)
} 
pode ser modificada silenciosamente por interpretações que desequilibram a balança da normatividade e facticidade em favor desta última.

Considerados esses limites às mutações constitucionais, resta perquirir qual o papel do Tribunal Constitucional no controle dessas modificações informais, uma vez que a sua tarefa é a guarda da Constituição mediante a jurisdição constitucional. Partindo dessa premissa não poderia ser outra a conclusão a não ser que cabe ao Tribunal Constitucional o controle imediato, direto e permanente das mutações constitucionais para evitar a ruptura entre as prescrições da Lei superior e a realidade política e social.

Para Uribe Arzate e Esquivel:

[...] el Tribunal Constitucional se configura como el órgano jurisdiccional del proceso formal de reforma y, habida cuenta que también el proceso de configuración de las mutaciones constitucionales debe ser objeto de control, nos parece que al proprio Tribunal Constitucional corresponde tan encomiable tarea. A mayor abundamiento, podemos señalar que el Tribunal Constitucional puede conocer de todo lo que a su parecer contraríe a la Constitución. ${ }^{21}$ (2012, p. 219)

Ainda quanto à atuação do Tribunal Constitucional, digna de destaque a afirmação de Pegoraro:

[...] mesmo que o Tribunal Constitucional esteja autorizado a realizar unicamente o controle "formal" da revisão constitucional, a Corte pode alterar o sentido das palavras. [...] os Tribunais Constitucionais foram definidos por estudiosos de todas as partes do mundo - juristas e politólogos- como «poder constituinte permanente», «ilha da razão no caos das opiniões», «aristocracia com vestidos modernos»... Trata-se, entretanto, no caso dos Tribunais, não de uma aristocracia de sangue senão antes, uma aristocracia do saber, introduzida nesse mesmo em seu próprio papel, não em virtude de uma conexão direta com o corpo eleitoral, senão com base em outros critérios, sendo o primeiro de todos o conhecimento e a formação profissional. (p. $18 ; 19$, em fase de elaboração)

Portanto, inegável a relação entre as mutações constitucionais, sua incidência no texto constitucional e o controle permanente pelo Tribunal Constitucional. No Brasil, cabe ao Supremo Tribunal Federal fazer esse controle sobre os demais poderes e sobre suas próprias decisões que impliquem alteração do conteúdo constitucional sem mudança do texto.

O extenso rol de direitos e garantias previsto no corpo constitucional de 1988 e a necessidade de operacionalizar tais normas aos anseios do corpo social tornou mais requerida a atuação da jurisdição constitucional, que poderá atuar direta e indiretamente para mudar o

\footnotetext{
21 “[...] o Tribunal Constitucional se configura como o órgão jurisdicional do processo formal de reforma e, tendo em vista também que o processo de configuração das mutações constitucionais deve ser objeto de controle, nos parece que ao próprio Tribunal Constitucional corresponde tão louvável tarefa. Além disso, podemos dizer que o Tribunal Constitucional pode conhecer tudo o que na sua opinião contrarie a Constituição." (tradução nossa)
} 
conteúdo constitucional, ao escolher ou privilegiar determinados valores em detrimento de outros.

\section{CONSIDERAÇÕES FINAIS}

As Constituições, assim como todo o ordenamento jurídico, devem acompanhar as contínuas transformações políticas e sociais. Contudo, mudanças constantes enfraquecem a sua força normativa e supremacia, bem como conduzem a um cenário de insegurança jurídica.

Nesse sentido, a reforma constitucional somente poderá ser considerada o mecanismo mais adequado e producente de adaptação da Constituição se respeitar os seus limites formais e materiais, mas também se for utilizada de maneira excepcional e quando realmente necessária, sob pena de seu uso indiscriminado fragilizar toda a estrutura constitucional do Estado. 
Como visto, a mutação constitucional é uma modificação não formal da Constituição, que altera o sentido e o conteúdo da norma sem mudar o seu texto, podendo ser empreendida pelos costumes ou convenções constitucionais, bem como por atos normativos e pela atuação da jurisdição constitucional.

Assim, a mutação constitucional é uma alternativa apropriada para a mudança do conteúdo constitucional, desde que não ultrapasse os seus limites, notadamente a supremacia da Constituição, e cabe à Corte Constitucional defendê-la, seja na aplicação pelos demais poderes, seja na interpretação que ela própria realiza por meio da jurisdição constitucional.

No Brasil, a regra tem sido o emprego da reforma constitucional por meio de emenda. Todavia, a modificação formal da Constituição de 1988 por mais de noventa vezes em menos de trinta anos tem enfraquecido a supremacia constitucional e abalado todo o ordenamento jurídico e institucional do País. Assim, defende-se que a mutação constitucional é uma opção à emenda constitucional e o órgão mais adequado para utilizá-la é o Supremo Tribunal Federal.

\section{REFERÊNCIAS}

BRASIL. Constituição da República Federativa do Brasil (1988). Disponível em: <http://www.planalto.gov.br/ccivil_03/Constituicao/Constituicao.htm>. Acesso em: 01 set. 2016.

BULOS, Uadi Lamêgo. Da reforma à mutação constitucional. Revista de informação legislativa, v. $33, \quad$ n. 129 , p. 25-43, jan./mar., 1996. Disponível em:<http://www2.senado.leg.br/bdsf/item/id/176380>. Acesso em: 25 jul. 2016.

CAnotilho, J. J. Gomes. Direito Constitucional e Teoria da Constituição. $7^{\mathrm{a}}$ ed. Almedina. Coimbra, 2003. 
CLÈVE, Clèmerson Merlin; LORENZETTO, Bruno Meneses. Governo democrático e jurisdição constitucional. Belo Horizonte: Fórum, 2016.

DE VEGA, P. La reforma constitucional y la problemática del poder constituyente. Tecnos. Madrid. 2007.

JELLINEK, G. Reforma y mutación de la Constitución. CEPC. 1991.

HESSE, Konrad. A força normativa da Constituição. Porto Alegre: Sergio Antonio Fabris Editor, 1991.

HSÜ DAU LIN. La mutación constitucional. Ivap. Oñati. 1998.

LASSALLE, Ferdinand. A essência da constituição. Rio de janeiro: Liber Juris, 1988.

LOEWENSTEIN, K. Teoría de la Constitución. Ariel. Barcelona-Caracas-México. 1979.

LUCAS VERDU, P. Curso de Derecho Político. Vol. 4. Tecnos. Madrid. 1984.

MINAYO, Maria Cecília de Souza. Pesquisa social: teoria, método e criatividade. 23. ed. Petrópolis, RJ: Vozes, 2004.

MIRANDA, Jorge. Teoria do Estado e da Constituição. $3^{a}$ ed. Forense. Rio de Janeiro. 2011.

PEGORARO, Lucio. Revisões informais da Constituição. Artigo inédito (em fase de elaboração).

RAMOS, Paulo Roberto Barbosa. O conceito de constituição em Ferdinand Lassalle. Porto Alegre: Sergio Antonio Fabris Editor, 2012.

SACCHETTO, Thiago Coelho. As mutações constitucionais no contexto brasileiro de crise da representação democrática. e-Pública, Lisboa , v. 2, n. 1, p. 123-140, jan. 2015. Disponível em <http://www.scielo.mec.pt/scielo.php?script=sci_arttext\&pid=S2183-184X201 5000100007\&lng=pt\&nrm=iso >. Acesso em: 08 ago. 2016.

SANTOS, Carlos Victor Nascimento dos. "Mutação à brasileira": uma análise empírica do art. 52, x, da constituição. Rev. Direito GV, São Paulo, v. 10, n. 2, p. 597-614, Dez. 2014. Disponível em: <http://www.scielo.br/scielo.php?script=sci_arttext\&pid=S1808-2432201400 0200597\&lng=en\&nrm=iso>. Acesso em: 08 ago. 2016.

SILVA, José Afonso da. Mutationes constitucionales. Cuestiones constitucionales. 1. México: Instituto de Investigação Jurídica, Universidad Nacional Autónoma de México, 1999.

SILVA, José Afonso da. Aplicabilidade das normas constitucionais. 7. Ed. São Paulo: Malheiros, 2007. 
SCHMITT, Carl. Teoría de la Constitución. Alianza. Madrid. 2011.

URIBE ARZATE, Enrique; CORREA ESQUIVEL, Grisel Alejandra. Mutaciones constitucionales y la problemática de su control en el Estado constitucional. Rev. Derecho, Barranquilla , n. 38, p. 196-224, Dez. 2012. Disponível em: < http://www.scileo. org.co/scielo.php?script=sci_arttext\&pid=S0121-86972012000200007\&lng=en \&nrm=iso $>$. Acesso em: 08 ago. 2016. 